Peer-Reviewed Article

ISSN: 2162-3104 Print/ ISSN: 2166-3750 Online Volume 7, Issue 4 (2017), pp. 1030-1047 (C) Journal of International Students http://jistudents.org/ doi: 10.5281/zenodo.1035959

\title{
Problematic Areas of Host University Support Services for Short-Term Mobility Students
}

\author{
Adriana Perez-Encinas \\ The Autonomous University of Madrid \& Research Institute on Higher \\ Education and Science (INAECU), Spain \\ Jesus Rodriguez-Pomeda \\ The Autonomous University of Madrid \& Research Institute on Higher \\ Education and Science (INAECU), Spain \\ Mikuláš Josek \\ Czech University of Life Sciences Prague, Czech Republic
}

\begin{abstract}
The growing numbers of mobile students over the years made the provision of student services a key topic of interest for higher education institutions. In order to offer a better experience for international students, it is important to be aware of and assess their needs in relation to different sets of support services. The data used in this paper were gathered through the ESNsurvey 2016 project, a research venture focused on the experiences of participants in short-term student mobility in Europe. Responses were collected from 12,365 international students, who have participated in a short-term (3-12 months) study period abroad mostly through Europe's most promoted mobility program called ERASMUS+. For the purpose of this paper, the focus was only on the aspect of host university support services. The comments of 2,012 students about their experiences were analyzed using a probabilistic methodology known as Latent Dirichlet Allocation (LDA). The
\end{abstract}


findings reveal that some international students' concerns are not fully addressed by higher education institutions. The main problem areas identified with respect to host support services were admission, living costs, including accommodation and money concerns, and IT and bank issues. It is strongly recommended that universities address the problematic areas through student support services by assessing international students' opinions and needs.

Keywords: ESNsurvey, host university support services, international students, LDA

The number of mobile students more than doubled between 2005 and 2012 (OECD, 2015). In Europe, the focus is on short-term study stays and work placements, which are promoted through the ERASMUS+ program. In the 30 years of existence of the ERASMUS+ program, 4.4 million students and trainees have participated in an abroad experience, with just over 300,000 in 2014/15 (European Commission, 2017). We can expect a continuous increase in student mobility and greater support for the ERASMUS+ mobility program, because the European Union has the ambitious goal that $20 \%$ of graduates in higher education will have had an experience of studying abroad by 2020 (Council of the European Union, 2011).

In fact, the growing numbers of mobile students over the years made the provision of student services a key topic of interest in relation to the process of internationalizing higher education (Perez-Encinas, 2015). With the accompanying developments in the area of goods and services, even universities are starting to focus on providing quality services for not only local but also international students. Since higher education institutions can be partly funded by international students' tuition fees, the rise in the number of prospective international students benefits institutions in the long run. Moreover, the presence of international students at universities can be seen as a major contribution to enriching campuses with cultural diversity, pluralism, and opportunities for intercultural learning and engagement (Willer, 1992). Against this backdrop, as Choudaha (2017) claims, institutions have to balance the inflow of foreign students with support services that not only enable students to pursue their studies, but also satisfy their career and employability expectations. Therefore, providing support services can become a key issue in the internationalization of higher education process. It is relevant for our study to identify how international- 
friendly institutions in Europe operate and to focus on the major problem areas for international students when studying abroad, in order to improve the service provision, and therefore the satisfaction of international students with their study abroad experience.

\section{LITERATURE REVIEW}

According to Knight (2008), the internationalization of higher education is "the process of integrating an international, intercultural and global dimension into the purpose, functions, and delivery of higher education at institutional and national levels" (p. 11). The scope of the term "internationalization" is very broad; it encompasses physical mobility, recognition of studies, knowledge transfer and many more aspects. Since universities tend to introduce more and more measures (e.g., support services and integration activities for foreign students) with the aim of establishing a more international way of teaching and providing services, the focus of this paper is the potential problems international students face in this respect.

International students of the ERASMUS+ program might be different from other student migrants in other parts of the world due to the program's conditions. Students of ERASMUS+ do not pay tuition fees at foreign universities and the scholarships they receive should also cover travel costs and accommodation abroad.

According to Teichler (2009), most students in Europe consider the idea of doing at least part of their studies in another country a viable and meaningful opportunity. He also claims that the ERASMUS+ program has brought a change in the perception of international students regarding higher education. Compared to the past, when students flowed mainly from developing to developed countries (vertical mobility), ERASMUS+ students are now expected to be, on average, at least as good as local students (horizontal mobility) in their level of knowledge and skills. In addition, it appears that Erasmus students critically compare study materials and conditions of the host and home institution and use this information to request improvements.

Murphy-Lejeune (2002) compared Erasmus students with other migrant groups in an ethnographic study. The Erasmus students differed from the other groups in terms of their lower age and the associated higher motivation and greater ability to adapt. It can be said that, compared to the other migrant groups, they were the most prepared to take advantage of the 
opportunities they had. A shorter length of stay allowed them to preserve their culture, but partly prevented them from immersing themselves in the cultures of the countries they visited.

For international students, who might be accustomed to different approaches to education, a mismatch between expected and experienced quality and efficiency of services provided by their receiving institution can contribute to an increase in acculturative stress (Khawaja \& Smith, 2011) and thus to impaired adaptation (Khawaja \& Dempsey, 2008) and higher levels of depression (Ward et al., 2001). Sherry et al. (2004) found such a mismatch in both foreign and local students, where foreign students were more critical of the quality of educational services than local students.

According to the Erasmus Impact Study (Brandenburg et al., 2015), the increasing number of incoming (and outgoing) students under the ERASMUS+ program has led to a growing awareness of the need for support services and to an emphasis on simplifying administrative procedures. Kelo et al. (2010) recognize that "student support" and "student services" can apply to a wide range of activities and services offered to students, such as providing information, arranging accommodation, providing access to dining facilities, offering welcoming activities, or offering academic or language support.

Although the need for support services for students is gaining in importance, their specific needs and desires, from the point of view of international students themselves, have still not been clearly defined (see Kelo, Roberts \& Rumble (2010) regarding non-European students). According to the American Council of Education (2015), it is not easy to figure out the best way to meet the needs of international students. Indeed, Perez-Encinas and Ammigan (2016) agreed that international students at one single institution face differing issues, so they might need a diverse set of support services.

International students go through various stages during their stay at the host institution. During these stages, the students have different needs that require different services. Generally, we can divide the stages of a study abroad period into the stage before the departure (services related to providing information and preparing students to study in another country), the stage shortly after arrival (services related to the immediate adaptation of a student), the rest of the study period (services related to integration into the local community), and the period after returning to their home country (services related to re-entry or reintegration into the home university). However, this last stage has not been deeply analyzed in the literature. 
Studies showing the stages and the distribution of student support services are, for example, those of The Higher Education Academy (2015), which provides the International Student Lifecycle, in which several support services are represented. Other authors that discuss the topic are Kelo, Roberts and Rumbley (2010) and Archer, Jones and Davidson (2010).

According to the aforementioned stages, welcoming days or orientation weeks are among the most important support services in the second stage of the International Student Lifecycle (Higher Education Academy, 2015). These services assist international students to integrate into the new environment. They usually involve the communication of initial information and certain orientation or integration activities with other international and local students. Leask (2009) emphasizes the need for facilitating meaningful interaction between home and international students, both inside and outside the classroom. These services can facilitate the initial process of adaptation; they help students to familiarize themselves with the life at the host university and to integrate faster.

One of the major challenges before arrival or shortly after arriving in a new country is securing short-term accommodation, which is closely linked to the financial issues of the foreign student. Poyrazli and Grahame (2007) highlighted this practical challenge and Tolman (2016) found that housing international and domestic students together through a roommatepairing program brought certain benefits for participants in the program, as well as for the university. The complex issue of housing students of the ERASMUS+ program is being researched in an ongoing project called HousErasmus + (HouseErasmus, n.d.). Arranging accommodation or at least guidance in finding accommodation is one of the basic services that a receiving university could provide to the visiting student.

Another possible support service that can be offered before international students arrive on campus is the "buddy program," in which local students welcome (and often directly pick up) and help incoming international students with solving the necessary tasks immediately upon arrival at their host university (e.g., obtaining a student card or public transport pass). Local students volunteer to participate in the buddy program in order to practice their foreign language skills and establish friendships with international students from all over the world. Campbell (2012) revealed that the systematic pairing of local and international students contributes to befriending locals and helps newly arrived students to adapt. The local student buddy who strives for linguistic and cultural exchange is usually the first contact person for the incoming student upon arrival. The 
buddy program is often coordinated by the international relations department of the university or the international student club.

A number of universities have student clubs or associations that cater to the social needs of international students. For example, Erasmus Student Network (ESN) clubs are present at more than 500 universities in 40 countries around Europe (Find your ESN section, 2017). Student clubs help in the process of adaptation and integration of foreign students, which has been recognized by a partnership with the DG Education and Culture Department of the European Commission (ESN.org, 2017). ESN has investigated the satisfaction of international students with their student clubs and found that more than half of the international students "completely agreed" or "rather agreed" that ESN activities helped them to better integrate with local students (Escrivá Muñoz et al., 2015). We therefore argue that this service should be provided by student associations and should be offered during the stay of international students at all host universities.

Of course, there are also many other services that can enhance the experience of international students at the host institution. Some of these are offered during specific stages of their learning cycle but others can be offered throughout their stay. In fact, support services such as a local language courses, courses on the local culture of the visited country, or a combination of these are offerings that overlap with educational courses. It is generally expected that studying abroad brings great benefits; students improve their skills in the language of the visiting country, as well as in understanding cultural differences and in different aspects of intercultural communication (Behrnd \& Porzelt, 2012). Those aspects, together with their educational experiences, enrich the personal and professional lives of the students. Thus the continuous development in internationalization challenges institutions to reorganize the curricula and services they offer.

The literature review aimed to investigate the problems international students of the ERASMUS+ program might have throughout their study abroad experience and how these can affect them. Higher education institutions can diminish some of these problems through student support services, but should be well informed about which problems are the most crucial and how students perceive them, which is the issue that this paper tries to address. Therefore, we analyze qualitative data in the form of comments related to major problems that students faced and aim to clarify the importance of student support services in addressing these issues. In the next section the methodology and the data collection procedure of this study are explained. 


\section{RESEARCH METHOD}

A qualitative, unsupervised method based on Bayesian probability was used to analyze the data. The latter was sourced from the ESNsurvey 2016 project (Josek et al., 2016), the main topic of which was the "internationalfriendliness of universities." The aim of the survey was to explore the role of host-university services, academic support, intercultural contact, and friendship networks in relation to satisfaction with the study abroad experience.

\section{Data collection procedure}

The data used in this report were collected through an online questionnaire titled "ESNsurvey 2016 Questionnaire" posted online at www.esn.org/esnsurvey/2016. The link was distributed through local associations of one of the largest student networks in Europe, namely the Erasmus Student Network AISBL (ESN). ESN has more than 500 branches at various universities and in Europe. The link was sent to all the branches through institutional channels, as well as via social media. Moreover, important dissemination actions were carried out by the international offices of universities, which supported the project idea and the local ESN association by sending the questionnaire to their students. Additionally, other important dissemination channels were accessed through cooperation with the European Commission, the National agencies for the ERASMUS+ program and other institutional partners in the field of higher education. Consequently, the questionnaire was sent to a broad audience and not only to ESN's main contacts.

The questionnaire was disseminated through a "snowball" technique that enabled it to reach a very large number of potential participants, but this did not allow for a calculation of the return rate. The data collection period lasted from the 16th of October 2015 to the 8th of January 2016. The questionnaire reached students from 106 countries. These students were studying mostly in the European Higher Education Area. The highest number of answers was collected from the following countries: Italy $(2,230)$, Spain $(2,041)$ and Germany $(1,145)$.

The basic characteristics of the sample were as follows: $67 \%$ of the respondents were female and $33 \%$ male. In fact, the number of female respondents predominates in the total group of all mobile students participating in the ERASMUS+ program (European Commission, 2015). The average age of the respondents was 23. Most of the respondents were at 
the bachelor level of studies (74\%) and the rest were master's level students (26\%). Another analyzed variable was the socioeconomic status of the respondents through a question about family income. The majority of the students $(63 \%)$ perceived their families' incomes as average.

For the main questionnaire, homecoming exchange students who had completed a short-term study abroad (one to two semesters) were targeted. However, first a pilot questionnaire was filled in by approximately 20 students face-to-face and then posted online. The online questionnaire was filled in by approximately 50 students. The data collected through the questionnaire were used to analyze students' experiences and satisfaction with their exchange period abroad. The questionnaire comprised 67 questions (mainly closed questions and few open questions). ESN has developed annual surveys for the past 11 years, through which 150,000 responses have been collected so far. In fact, on average 14,000 answers per year are compiled in an annual publication called the "ESNsurvey Report." A similar number of responses was gathered from homecoming international students for this current study, with a final count of 12,365 valid responses.

The questionnaire contained different areas of analyses and variables: European student mobility flows, host university support, academic adaptation, social adaptation and home university reintegration. For the purpose of this paper, we focused on only one of the aforementioned variables "host university support services," which relates to those services provided once the international student arrives at the institution. From the many possible host university support services, we chose seven areas: accommodation assistance, buddy program, welcome presentation, orientation week, student associations, local language course and cultural adaptation course.

Moreover, we analyzed data collected from responses to the following question: "Did you have major problems with any of the following topics at your host university?" The options were: admission, enrollment in courses, course schedule and exam schedule, accommodation, finances, visa, mental health issues (e.g., depression), health problems, information technology (e.g., no internet connection), student restaurant/cafeteria (e.g., food issues related to religion). Students could reply with an affirmative "yes", a negative "no" or with the option "yes, with a comment." International students could also select the option "other" and reflect on their own experiences with problem areas in their host university support services, as well as commenting on each of their aforementioned options in an open question. Hence, we based our analyses 
on qualitative data collected through this open question, which returned 2,012 answers in the format of a comment.

\section{Analysis}

In order to analyze the 2,012 comments about the major problem areas related to support services for international students, we employed a basic text mining method "to identify identifying patterns in a corpus" (Brett, 2012, p.1). We used topic-modeling algorithms, which facilitate distant reading through a topic model, because this enables one to deal with the corpus of texts as a whole, not only individual texts. Topic modeling is premised on the assumption that each of the texts within a corpus is a topic built from the themes discussed by the text's author (Mohr \& Bogdanov, 2013; Meeks \& Weingart, 2012).

One of the basic probabilistic topic models is the Latent Dirichlet Allocation (LDA) (Blei, 2012). LDA is a statistical model that assumes that any text is the result of a probability distribution over sets of words (called topics). We ran the LDA statistical model with our data set $(2,012$ comments) by using MALLET 2.0.7 (a Machine Learning for Language Toolkit, McCallum, 2002). This is open source software designed to enable text classification and information extraction.

The international students' comments about host university support services were reviewed and processed to identify duplicates or datasets in different languages, as well as very common words (known within this methodology as stop-words) that do not add any relevant content to the analysis (DiMaggio, Nag, \& Blei, 2013). The identified stop-words were removed to develop an LDA model. After running the LDA model and MALLET, we obtained a table that gathered each topic's relative percentage contribution into the composition of each student's perception text. These percentages can be considered the weight of the links between discourses and topics (Graham \& Blades, 2012). The authors proposed a label to name each topic, as seen in both tables (Table 1 and 2). The data represent the topics that had the highest probability in the composition of each student's perception file. The composition probabilities can be interpreted as the weights of the connections' strengths (Meeks, 2011).

The resultant topics were coded with a label name, as can be seen in Table 1. The labels are as follows: academics, admission and enrollment to courses, health issues, IT connections \& bank issues, language, restaurant, and living expenses (including accommodation and finances).

This method is usually applied to big datasets to discover the main 


\section{Table 1: Topics after running the probabilistic topic model}

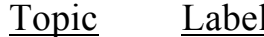

$0 \quad$ Academics

$1 \quad$ Admission

$2 \quad$ Health issues

3 IT connection \& Bank issues

$4 \quad$ Admission

5

Language

6

Restaurant

7

Living expenses
(accommodation)

8

Living expenses

(Finances)

$9 \quad$ Admission (enrollment to courses)

Note. Authors' compilation (2017)
Main words in this topic

exchange master student students department year bachelor home process project things degree studying modules complicated module admission accepted enrollment visa permit residence erasmus EU students police turkey student time long country embassy exam university issue exchange programme months

health problems problem issues doctor insurance hospital time bad depression country mental care friends doctors sick good felt

internet connection wifi dormitory residence bad work dorm student problems bank card needed problem weeks account open university home erasmus host back told admission office problem student semester send beginning end arrived time arrival days English students language speak Spanish local people erasmus school foreign teachers level international spoke class office professors staff

food cafeteria student restaurant eat vegetarian expensive options vegan restaurants normal day big prices offer canteen campus cheaper accommodation room find university flat accommodation students student hard place time expensive found good people difficult problems offered erasmus grant money pay month finances expensive country scholarship months rent living financial cover expenses costs abroad support high

courses university schedule exams students classes problems time enrollment home host information agreement change semester lot learning choose 
latent themes in a set of words. Thus, we built a probabilistic topic model based on the 2,012 comments we had obtained to draw conclusions regarding their major problem areas with respect to host university support services provision abroad by using a large database and a probabilistic approach. The next section comprises the results after running MALLET with 10 topics and a discussion. Moreover, the most common topics for international students on host university support services, as categorized by label and weight, are identified.

\section{RESULTS}

Due to the importance of gathering international students' opinions in a comprehensive way, we analyzed only the results that were collected in response to one open question, in which international students were asked about major problem areas with respect to service provision. Thus, we present a qualitative analysis of the results obtained by using a basic text mining program (LDA) and by clustering the topics under 10 different labels after running MALLET. The topics were labeled by the authors in order to find connections between them and, consequently, to find several clusters or groupings. The results can be seen in Table 1 below.

The results after analyzing the topics of international students' comments on the major problem areas concerning host university support services and running the 2,012 comments through MALLET show the following results based on weights and connection strengths (see Table 2).

\section{Table 2: Common topics categorized by label}

$\begin{array}{ll}\frac{\text { Topic }}{9} & \text { Label } \\ 7 & \text { Admission } \\ 4 & \text { Living expenses } \\ 8 & \text { Admission } \\ 3 & \text { Living expenses } \\ 5 & \text { IT connection \& Bank issues } \\ 2 & \text { Language } \\ 0 & \text { Health issues } \\ 1 & \text { Academics } \\ 6 & \text { Admission } \\ & \text { Restaurant }\end{array}$

Note. Authors' compilation (2017) 
After analyzing the perceptions of international students regarding host university support services, we identified the topics (main words on the topic) with stronger weights and connections (Meeks, 2011). This indicated the major areas that needed improvement in the service provision at higher education institutions. In this sense, our findings show that the major problem areas that international students face with host university support services at universities are related to admission services such as enrollment to courses, living expenses, with accommodation being the predominant one, finances and IT connection. In fact, the respondents did not comment on finding problems with services such as: language, restaurants/cafeteria, or mental health issues.

The main area in need of improvement is admission (topic 9,4 and 1). The students' discourse and comments related directly to support services linked to courses, exams, beginning and ending dates, agreements, visa issues and permits of stay, course information and schedules. The second main area for improvement indicated by the results is living expenses (topic 7 and 8). This area is dominated by comments about the Erasmus grant, money, accommodation, expensive flats and difficulties covering the costs. The next concern and most commented upon issue was IT connection and bank issues (topic 3). International students commented on issues related to the accessibility of the internet through WI-FI and on difficulties with opening a bank account. These last two issues can be of great importance because the first links the international students directly to their family and friends at home and abroad, and the second one to the living expenses issue. Languages services, health services, and restaurants /cafeterias were not identified as main problem areas.

\section{Limitations}

The results of this study are based on comments related to several host university support services by international students from European Union countries only. This is because the data collection was promoted and done via European networks and stakeholders, in which the main participants were ERASMUS+ program students. In this sense, the results might vary for other international students depending on data collection and region specifics. Moreover, we understand that the study can be deepened if more services are taken into account. It is important to mention that not all institutions of higher education offer the same range of services, so analysis and perceptions of international students might vary from institution to institution. 


\section{DISCUSSION}

According to our results, international students agreed on a series of problem areas related to being abroad by commenting on factors that influenced their stay abroad. Notably, nearly two decades ago, Li and Kaye (1998) identified five common factors influencing international students' perceptions of their learning environment and learning experience, namely: financial problems, integration problems when mixing with local students, academic progress, English proficiency, and accommodation. Comparing both sets of results, we identify that admission and living expenses issues connected to finances are still an unresolved issue and are two of the major concerns for students while abroad. We therefore encourage universities to provide international students with detailed information on admission issues (e.g., enrollment to courses, Visa, accommodation information and options), as well as mobility schemas to smooth out issues relate to living expense and finances. These actions should be taken, not only by those working in the international office, but by all employees on campus working with support services. Indeed, providing services to more international students is becoming central to the work of all student affairs professionals at the university, not just those who work in the international office (ACE, 2015).

Another important conclusion is related to the provision of IT connections and bank issues. While internet connections might be seen as less important than other services, it is actually of immense concern for students who need to connect with their families and communicate with friends to avoid psychological implications of being unable to do so. Lack of connection with relatives through wireless mobile devices (WMD) can increase students' anxiety (Cheever et al., 2014). This result can be an expression of psychological dependency when students' are heavy or moderate WMD users. Our result is also aligned with relationships found in the literature between high frequency cell phone use and students' health and behavior, with interesting effects on their academic performance (Lepp et al., 2013) and well-being (Yildirim \& Correia, 2015). Bank issues are also related to information activities; universities should offer accurate information on banking options in order to accomplish international students' satisfaction and a better experience. Bank issues are connected to more general finance issues that, as the literature explains, affect international students and satisfaction (Woodall et al., 2014). Finance issues are at the heart of students' analysis of the value for money of their 
experience. But it is important to keep in mind the figure of the so-called "student-consumer" is an effect of the growing marketization of higher education (Tomlinson, 2016), a process that does not capture all the benefits (intellectual, moral, cultural) that emerge from an international higher education experience. Finally, the next section concludes the paper with the main findings, reflections, and recommendations.

\section{CONCLUSION}

This study was motivated by a lack of up-to-date data collected by higher education institutions to assess international students' needs when they go abroad. The increasing number of inbound and outbound students has led to an increased awareness of the necessity of providing support services (Brandenburg et al., 2015), highlighting the importance of higher education institutions being aware of international students' opinions and needs in order to provide quality student support services. It is important to fulfill the expectations of international students with the service offered in order to increase their satisfaction with their stay abroad. Five major areas were identified as the ones that caused major problems for international students, according to the ESNsurvey 2016 data. These are: admission (enrollment in courses, Visa issues), living expenses such as accommodation or finances, and IT connection, and bank issues. All of them are related to problems that might arise during the first and second stage of the International Student Lifecycle (The Higher Education Academy, 2015). A clear need for assessment tools should be recommended to higher education institutions, in order to help them to listen and understand the changes that are happening, not only on the institutional level of universities, but also in the minds and feelings of students.

\section{REFERENCES}

American Council on Education, ACE. (2015). Internationalization in action. Retrieved from: https:/www.acenet.edu/newsroom/Pages/Internationalization-in-Action.aspx [Accessed October 2016].

Archer, W., Jones, E., \& Davison, J. (2010). A UK guide to enhancing the international student experience. UK Higher Education International Unit Research Series/6. London: UK HE International Unit.

Behrnd, V., \& Porzelt, S. (2012). Intercultural competence and training outcomes of students with experiences abroad. International Journal of Intercultural Relations, 36(2), 213-223. doi:10.1016/j.ijintrel.2011.04.005 
Blei, D. M. (2012). Probabilistic topic models. Communications of the ACM, 55(4), 77-84.

Brandenburg, U., Taboadela, O., \& Vancea, M. (2015). Mobility matters: The ERASMUS impact study. International Higher Education, 82, 5-7. doi:10.6017/ihe.2015.82.8863

Brett, M. R. (2012). Topic modeling: A basic introduction. Journal of Digital Humanities, 2(1), 1-5.

Campbell, N. (2012). Promoting intercultural contact on campus: A project to connect and engage international and host students. Journal of Studies in International Education, 16(3), 205-227.

Cheever, N. A., Rosen, L. D., Carrier, L. M., \& Chavez, A. (2014). Out of sight is not out of mind: The impact of restricting wireless mobile device use on anxiety levels among low, moderate and high users. Computers in Human Behavior, 37, 290-297. http://dx.doi.org/10.1016/j.chb.2014.05.002.

Choudaha, R. (2017). Three waves of international student mobility (1999-2020). Studies in Higher Education. 43(5), 825-832. doi: 10.1080/03075079.2017.1293872

Council of the European Union (2011). Council conclusions on the modernisation of higher education: 3128th Education, Youth, Culture and Sport Council meeting. Retrieved from:

,www.consilium.europa.eu/uedocs/cms_data/docs/pressdata/en/educ/12637 5.pdf.

DiMaggio, P., Nag, M., \& Blei, D. M. (2013). Exploiting affinities between topic modeling and the sociological perspective on culture: Application to newspaper coverage of U.S. government arts funding. Poetics, 41, 570606.

European Commission (2015) Erasmus statistics: Facts, figures and trends, 20132014.

Retrieved

from

http://ec.europa.eu/dgs/education_culture/repository/education/library/stati stics/erasmus-plus-facts-figures_en.pdf [Accessed May 2017].

European Commission (2017). Erasmus + Programme annual report 2015. [Online], Available at: https://ec.europa.eu/programmes/erasmusplus/sites/erasmusplus/files/erasmus-plus-annual-report-2015.pd

Escrivá Muñoz, J., Helm, B., Perez Encinas, A., Stasiukaitye, J. \& Zimonjic, B. (2015). Local integration, economic impact and accompanying measures in international mobility: Research report of the ESNSurvey 2015. Brussels: Erasmus Student Network AISBL.

ESN.org. (n.d.). Retrieved from https://esn.org/about

Find your ESN section. (n.d.). Retrieved from https://esn.org/sections

HousErasmus. (n.d.). Retrieved from https://houserasmus.eu/

Josek, M., Fernandez, J. A., Perez-Encinas, A., Zimonjic, B., de Vocht, L. \& Falisse, M. (2016). The international-friendliness of universities: Research report of the ESNsurvey 2016. Brussels: Erasmus Student Network AISBL. 
Kelo, M., \& Rogers, T. (2010). International student support in European higher education: Needs, solutions and challenges. Bonn: Lemmens.

Khawaja, N. G., \& Dempsey, J. (2008). A comparison of international and domestic tertiary students in Australia. Australian Journal Of Guidance \& Counselling, 18(1), 30-46. doi:10.1375/ajgc.18.1.30

Knight, J. (2008). Higher education in turmoil. The Changing World of Internationalisation. Rotterdam, The Netherlands: Sense Publishers.

Knight, J., \& de Wit, H. (Eds.). (1997). Internationalisation of higher education in Asia Pacific countries. Amsterdam, The Netherlands: European Association for International Education.

Leask, B. (2009). Using formal and informal curricula to improve interactions between home and international students. Journal of Studies in International Education, 13(2), 205-221.

Lepp, A., Barkley, J. E., \& Karpinski, A. C. (2014). The relationship between cell phone use, academic performance, anxiety, and Satisfaction with life in college students. Computers in Human Behavior, 31, 343-350. http://dx.doi.org/10.1016/j.chb.2013.10.049

Li, R. Y., \& Kaye, M. (1998). Understanding overseas students' concerns and problems. Journal of Higher Education Policy and Management, 20(1), 41-50.

Murphy-Lejeune, E. (2003). Student mobility and narrative in Europe: The new strangers. London, United Kingdom: Routledge.

McCallum, A. K. (2002). MALLET: A machine learning for language toolkit. Retrieved from http://mallet.cs.umass.edu/

Meeks, E. (2011, February 19). Comprehending the digital humanities [Web log message]. Retrieved from https://dhs.stanford.edu/comprehending-thedigital humanities.

Meeks, E., and Weingart, S. (2012). The digital humanities contribution to topic modeling. Journal of Digital Humanities, 2(1), 1-6.

Mohr, J. W., and Bogdanov, P. (2013). Introduction -topic models: What they are and why they matter. Poetics, 41, 545-569.

OECD (2015). Education at a glance 2015: OECD Indicators. Paris: OECD Publishing. http://dx.doi.org/10.1787/eag-2015-en

Perez-Encinas, A. (2015, December). The role of student associations in providing community involvement and integration between domestic and international students. Paper presented at 26th ISANA International Education Association Conference, Melbourne, Australia.

Perez-Encinas, A., \& Ammigan, R. (2016). Support services at Spanish and US institutions: A driver for international student satisfaction. Journal of International Students, 6(4), 984-998.

Poyrazli, S., \& Grahame, K. M. (2007). Barriers to adjustment: Needs of international students within a semi-urban campus community. Journal of Instructional Psychology, 34(1), 28-46. 
Sherry, C., Bhat, R., Beaver, B., \& Ling, A. (2004, July). Students as customers: The expectations and perceptions of local and international students. Paper presented at HERDSA Conference, Milperra, Australia.

Smith, R. A., \& Khawaja, N. G. (2011). Review: A review of the acculturation experiences of international students. International Journal of Intercultural Relations, 35, 699-713. doi:10.1016/j.ijintrel.2011.08.004

Teichler, U. (2009). Internationalisation of higher education: European experiences. Asia Pacific Education Review, 10(1), 93-106. doi:10.1007/s12564-0099002-7

The Higher Education Academy and UKCISA (2015). International Student Lifecycle Retrieved from: https://www.heacademy.ac.uk/node/10190

Tolman, S. (2016). Evaluation of an international roommate-pairing program (Doctoral dissertation), Rutgers University, New Brunswick, NJ.

Tomlinson, M. (2016). Student perceptions of themselves as 'consumers' of higher education. British Journal of Sociology of Education, 38(4), 450-467. http://dx.doi.org/101080/ 01425692.2015.1113856.

Ward, C. A., Furnham, A., \& Bochner, S. (2003). The psychology of culture shock. East Sussex: Routledge.

Willer, P. (1992). Student affairs professionals as international educators: A challenge for the next century. Working with international students and scholars on American campuses. Washington, DC: NASPA.

Woodall, T., Hiller, A., \& Resnick, S. (2014). Making sense of higher education: Students as consumers and the value of the university experience. Studies in Higher Education, 39(1), 48-67.

Yildirim, C., \& Correia, A.-P. (2015). Exploring the dimensions of nomophobia: Development and validation of a self-reported questionnaire. Computers in Human Behavior, 49, 130-137. http://dx.doi.org/10.1016/j.chb.2015.02.059

\begin{abstract}
ADRIANA PEREZ-ENCINAS, PhD, is a lecturer and researcher in business organizations and the internationalization of higher education at the Universidad Autónoma de Madrid (UAM) in Spain. She is a trainer for the EAIE Spring Academies. Since 2005 she has volunteered for the Erasmus Student Network, serving in various roles as national representative, president of the UAM chapter, project coordinator, and research member. She has recently been appointed as an evaluator for Spain's Erasmus+ National Agency. E-mail: adriana.perez.encinas@uam.es
\end{abstract}

JESUS RODRIGUEZ-POMEDA, $\mathrm{PhD}$, is an Associate Professor in Business Organization at Autonomous University of Madrid. His current research interests are related to leadership, management, strategy, and organization within Higher Education Institutions. Additionally, he serves as Vice-rector for Strategy and Planning at Autonomous University of Madrid. Email: jesus.pomeda@uam.es 
MIKULAS JOSEK is a $\mathrm{PhD}$ candidate, researcher, and teaching assistant at the Department of Psychology of the Faculty of Economics and Management of the Czech University of Life Sciences Prague (Czech Republic). He was a volunteer of the Erasmus Student Network as a Research Coordinator of the ESNsurvey 2016 project. He now coordinates the uni-buddy.com project and works in the Erasmus+ $\mathrm{HE}$ division of the Centre for International Cooperation in Education in Prague, CZ. E-mail: mikulas.josek@gmail.com 